\title{
Social Work and Social Protection in crisis circumstances - Organisation and activities of Centre for Social Work Banja Luka during the floods in 2014
}

\author{
Dragana Šćepović \\ University of Banjaluka, Faculty of Political Science \\ Andrea Rakanović Radonjić \\ University of Banjaluka, Faculty of Political Science \\ Ljubo Lepir \\ University of Banjaluka, Faculty of Political Science
}

\section{Abstract}

Modern man is at constant risk to his/her security, which threatens him/her from natural disasters. Today, these risks are much more frequent and intense than they were before. Climate change is affecting more and more extreme natural disasters that bring greater security risks. The most common risks that lead to crisis situations are related to extreme events during the escalation of natural disasters, such as: fires, floods, earthquakes, heavy rainfall, landslides, etc. These situations require adequate systemic responses, which are recognized through the actions of various institutions, mainly public institutions of public systems towards the vulnerable groups. Increased interest in the work of institutions and services in crisis situations comes from the need to seek effective responses to the existential vulnerability condition, but also to the condition of social need that is often associated with existential vulnerability. The paper presents organization and of work terms of the Centre for Social Work (CSW) in Banja Luka during the extreme floods in 2014, which hit this city twice in six months period. Conclusions and recommendations that have been defined, aimed at systematically improving the protection of the population and professionals in crisis situations at the local level are based on the results of the analysis of the activities that have been carried out and the Centre's direct actions, as well as an assessment of the achieved level of social protection and support to the population affected by the effects of the floods.

Keywords: social work, social protection, crisis, organisation, activities, social work Banja-Luka, the floods 


\section{Introduction}

Republic of Srpska is one of the two entities in Bosnia and Herzegovina that has its competencies, among which are social protection and the population protection in emergency situations.

Social protection, as an activity of special interest to the Republic, provides assistance to persons when they are in a state of social need and takes the necessary measures to prevent and eliminate the consequences of such a situation. Tis part of system has a significant role in protecting persons in natural disasters and other accidents. The Law on Social Protection of the Republic of Srpska ("Official Gazette of the Republic of Srpska" No. 37/12; 90/16; 94/19 and 42/20) recognizes a natural disaster as a special circumstance that leads to a state of social need. Centers for Social Work, as bearers of social protection at the local level represent important systemic subjects of protection in such situations they must provide adequate and efficient answers to the citizen's state of social needs.

The social need can be defined as a life situation in which an individual, family or group of people finds themselves, and need the help and support of others (individuals, systems) to overcome existential and social difficulties that they have in meeteng basic life needs. The consequences of natural disasters in extreme cases bring many into a state of social need. General material deprivation, endangerment of life, loss of loved ones, loss of safe housing, but also psychosocial and emotional problems are the consequences that natural disasters leave behind and and produce a state of social need. The State and its institutions have an obligation to respond to such situations, and to provide adequate assistance and support to the endangered so that they can overcome such a situation.

The key institutions implementing social protection measures in the Republic Srpska are Centers for social work (CSW). CSW through the mechanisms of the social protection system provides immediate assistance and support to those who need it. With approach "user in the center of attention", CSW ensures that system solutions are implemented in the best way in practice, that is, in the immediate living environment of the beneficiaries. In the conditions of emergency situations caused by natural disasters, the CSW provides the necessary material, but also psycho-social support to the beneficiaries, as well as to the professional workers who participate in providing assistance.

The Law on Social Protection defines the obligation of local government units to plan, organize and implement activities to prevent and remedy the consequences of the social needs of the population caused by various causes, including emergencies resulting from sudden natural disasters. Other legislation, Law on Protection and Rescue in emergency situations ("Official Gazette of the Republic of Srpska" No. 
$121 / 12$ and 46/17), defines emergency situation as a state in which the risks, threats or consequences of disasters (natural disasters), emergencies and other hazards to the population, life environment and material goods of such scope and intensity that their occurrence or consequences cannot be prevented or eliminated by regular action of competent bodies and services, due to which it is necessary to use special measures, forces and means for their mitigation and elimination "(Article 5) . In accordance with this definition of the concept of emergency, operation of CSW is recognized as primary and secondary. The primary activity of the CSW means direct activities carried out during a natural disaster, and the secondary activity means the activities of the CSW before and after a natural disaster where the existing system solutions arising from the Law on Social Protection are harmonized with possible and new situation. in which the resources of the system are additionally engaged in finding new solutions in order to respond to possible risks and the state of social need.

The CSW as one of the basic, leading institutions of the social protection system in local communities, in emergency situations has an extremely important role in protecting and rescuing the population, especially socially vulnerable groups, such as: people with disabilities, the poor, children, residents of collective accommodation, the elderly and infirm, etc. The position and role of the CSW in natural disasters arises from the general competencies defined by the Law on Social Protection, and are specifically determined by the Plan for protection against natural disasters and accidents prepared by local communities, based on the Decree on the content and manner of natural disasters and other accidents ("Official Gazette of the Republic of Srpska" No. 68/13). In order to fully understand the operation CSW during an emergency, it is necessary to keep in mind that the management of all protection and rescue resources in the Republic of Srpska is the responsibility of the Republic Emergency Headquarters, emergency headquarters at local government units and headquarters for emergency situations of companies and legal entities. This means that the operation of CSW must be under the direct authority of these institutions in order to align the overall activities with the priorities arising from the urgency imposed by the situation on the ground, and to identify CSW as a real resource of the overall rescue system. The Manual for the Centers for Social Work in Emergencies Caused by Natural Disasters (RS Ministry of Health and Social Welfare, 2015) clearly states that "protection and rescue is carried out by citizens, authorities, companies and other legal entities, rescue services, units and commissioners of civil protection, who also represent the subjects or forces of the protection and rescue system "(p. 27), whereby the focus of action is equally distributed to all actors involved in the rescue process. This empfisise the importance of the subjects of protection to a higher level, and the CWS as social institutions, were given a new dimension, initiators and creators of local programs of help and support for vulnerable categories of the population whose social sensitivity is especially pronounced in natural disasters. 
In May 2014, the Republic of Srpska was hit by a natural disaster whose consequences for property and persons at the time of the event were incalculable. It is a flood that affected more than a third of the territory of the Republic and a significant part of the area in the region. Three cities were completely flooded (Doboj, Šamac and Obrenovac in Serbia), while several other cities and municipalities were partially or mostly flooded. Unfortunately, the same natural disaster, but in a lesser extent, hit Republic of Srpska in August of the same year. During this period CWS, which were subjects of protection and rescue in local government units, operated in accordance with the Law on Protection and Rescue in Emergencies and other Republic of Srpska is an entity in Bosnia and Herzegovina that has its competencies in, among which are social protection and the population in emergency situations.. They also acted in accordance with the Law on Social Protection, which recognizes natural disasters as the cause of the state of social need. The CWS Banjaluka (Capital and administrative center of Republic) participated every time in providing direct help and support to the citizens when the river flooded the wider city area and when the lives of the citizens were endangered. The long-term operation of the Centre for Social Work Banja Luka has provided valuable experience in improving the systemic response to the state in natural disasters. These experiences are subject of interest of this paper.

\section{CWS Banjaluka organizational and material assumptions for acting in emergency situations}

For the efficient operation of the institutions in the system, existence of resources and a well-established management structure are of key importance for dealing with consequences of natural disasters, (Buljubašić, et al. 2015). According to the Rulebook on Internal Organization and Systematization of Workplaces in the Public Institution, the work of the CSW Banja Luka in regular circumstances is organized into three departments. The departments that are organizational units CSW Banjaluka are: Department of General Affairs, Department for Family and Legal Protection of Children and Families and the Department for Adults and the Elderly. In the Departments for Family and Legal Protection of Children and Families and the Department for Adults and the Elderly, jobs that carry out specialist-professional work are systematized, in accordance with the needs of priority groups of users. In the General Affairs Department, managerial positions and other positions are systematized in the vay to provide supports to professional work. In this Department are systematized positions directed towards the legal and financial functioning of CSW.

At the time when the catastrophic flood hit Banja Luka, the total number of employees in CSW in 2014, was 75. 49 had the status of professional workers, while the remaining 26 workers performed general work and had the status of other workers in social protection. Social workers have the largest share in the group of professional 
workers. There were no special jobs for carrying out activities related to emergency situations. Therefore, the success of acting in emergency situations depended on the same workers who performed regular activities of the institution, which indicated the need for good additional education of existing, primarily professional staff, related to content in the field of assistance, support and rescue.

At the time of the natural disaster, CSW Banja Luka, ie its employees, were burdened with a large number of beneficiaries of social protection measures and services. The number of beneficiaries immediately before the catastrophic floods was 21,070, which represented about $10.5 \%$ of the total population of Banja Luka according to the 2013 census. In just a few days, the number of those who sought help from CSW increased by 800 . The management of CSW had to count on a sharp increase of the number of beneficiaries. However, from the aspect of material and technical conditions and the human resources in the institution, we arise the questions Was CSW ready for such a development?!

From the material and technical means, it should be pointed out that the CSW Banjaluka at that time had a fully equipped and safe office space that was not endangered by floods, so that assistance activities could be managed without fear that it would be endangered. The mobility of professional workers was related to the use of three cars, none of which were prepared for extreme conditions of use.

In accordance with article 23 of the Law on Protection and Rescue, in emergency situations, organizations and companies are obliged to train and prepare protection and rescue teams and to hire them to perform protection and rescue tasks independently, as well as upon request. This provides the basis for CWS Banja Luka in November 2013 to adopt a Plan for protection and rescue from natural disasters and other accidents. This Plan clearly elaborates the obligations and activities that CSW must carry out in order to prepare for action in emergency situations. This Plan was important legal document in the preparation phase of the CSW emergency response. In the preparation phase, the management of the CSW Banjaluka complied with all the required elements defined by the Decree on the content and manner of drafting a plan for protection against natural disasters and other accidents. The result of these activities was a Plan for protection and rescue from natural disasters and other accidents. The development of the Plan was preceded by activities related to the preparation of results of risk assessment and assessment of the situation. All these activities were completed in November 2013, ie some six months before the catastrophic floods, when the preparation of the Plan for protection and rescue from natural disasters and other accidents, was completed. What was noticed as a shortcoming in the process of drafting the Plan is the non-implementation of parallel education and informing the employees of the CSW. The focus was on drafting a written document that should satisfy the form, ie the obligation of CSW to have an official document, while educating and informing employees was left aside. 
In contrast to the preparation, the more significant engagement of the CSW took place in the immediate action phase. The new situation has necessitated the need to seek quick answers to the growing needs of the population. Several standard and a couple of new, innovative activities have enabled consistency in activities, which has enabled the CSW to establish itself as an important entity in the process of providing support and assistance to citizens who are in a state of social need due to the consequences of catastrophic floods.

\section{Cooperation in the emergency management process}

In accordance with Mayor decision from mid May 2014 in Banja Luka, was declared a state of emergency due to the flood that hit the city. From that moment CSW Banja Luka made itself available to the Civil Protection of the City of Banja Luka. As a first step, the CSW compiled information on material and technical equipment and human potential, which could be placed in the protection and rescue service. At the same day, CSW Banja Luka passed a Decision establishing an Emergency Headquarters for responding to an emergency situation caused by a flood, and harmonizing working hours, jobs and tasks in accordance with the requirements of the emergency situation. During the emergency situation, the CSW continuously carried out activities in accordance with the orders of the City Crisis headquarters, and in cooperation with the Department of Civil Protection and the managers of checkpoints in the flooded areas. CSW Banjaluka organized work in three shifts, which provided coverage for all twenty-four hours a day. After first three days of declaring a state of emergency, when the workers of the CSW participated for twenty-four hours in rescuing and evacuating the population in the flood-affected areas, and in the distribution of basic foodstuffs, the work of the CSW was organized in two shifts. 07.00 hours was provided through "standby". This way of working was maintained until the Decision on declaring a state of emergency was repealed on May 26, 2014. During the August floods of the same year, in accordance with the City Mayor Decision, CSW adjusted its working hours in the same way, and again organized duty shifts 24 hours a day.

During the emergency situation in May and August 2014, 63 of 75 CSW employees were on duty and perform activities related to meeting the needs of the population and ensuring its safety. Twelve workers who did not participate in tih activities were on maternity leave or prevented due to age, illness or disability, which means that the organization of work is set quite broadly, covering all available staff.

\section{Bebneficiaries registration}

During the floods, and in accordance with the order of the Crisis headquarters of the City of Banja Luka, a Social Map was prepared. This included households that were endangered by the flood. A total of 2529 households whose housing units were flooded were listed, of which 1801 were completely flooded, while 289 households were partially flooded. The total number of enumerated household members was 7645 , of which 6284 people were endangered by the flood. These data refer to May 
2014. The same procedure in August covered 408 families. In the survey that was made participated 52 employees of CSW Banja, as well as 70 employees of the City Administration. The survey was conducted over a period of two days. For thir purpose professionals from CSW developed analytical questionnaire. The same instrument used in the following period.

This instrument was also used by Ministry of Health and Social Welfare to create a social map at the level of the entire Republic of Srpska. For data processing 80 people were engaged. Significant number of them was from CSW Banja Luka. Professionals from CSW Banja Luka also participated in the data processing managed by the Department of Informatics of the Banja Luka City Administration. The collected and processed data served for the distribution of humanitarian aid in the field. The professionals from CSW also directly participated in the distribution of humanitarian aid in the first five days after the declaration of the state of emergency, before these activities takes over Red Cross Banja Luka.

Professionals of CSW Banja Luka were engaged in the work of the Commission for collection, records and distribution of humanitarian aid for the City of Banja Luka. The main task of that Commission was to fairly and equally distribution of humanitarian aid to the population that was most endangered, according to the levels of priority. One of the activities of CSW Banja Luka was the networking of data and information on flooded areas and households, in cooperation with the Republic Red Cross.

\section{Population protection in the City areas affected by the floods}

In the activities of caring for the population of City that found itself in a state of social need caused by a natural disaster, the CSW directly participated in the protection and rescue of the people that was endangered by the flood. In the first days professionals from CSW were focused on taking care of people who needed accommodation. On the social anamnesis basis care was provided in the families of relatives or friends, shelters for adults and the, shelter for children and social welfare institutions in the City of Banja Luka.

After the emergency placement the professionals from CSW focused on activities related to the social protection rights for persons in a state of social need caused by natural disasters, as well as assistance in the procurement of. Some other activities, which were also in focus, were related to the distribution of basic foodstuffs to flood victims who were taken care of in the families of relatives or friends, and activities related to visiting institutions that accepted persons who lost their property. These activities included seeking an exit strategy for more permanent care of these persons. Activities related to planning further care were undertaken.

During these activities, over 3,000 field visits were made to the flooded population, more precisely, 2,529 home visits were made to flooded households, while the 
remaining number of field visits were made during the distribution of humanitarian aid, visits to temporary care centres, and field visits.

A particularly important activity was helping people from other areas who found themselves in the territory of the City of Banja Luka. These activities were aimed at helping families from the area of the City of Doboj, the municipality of Šamac and Obrenovac in the Republic of Serbia, which suffered the greatest damage from the floods in May 2014. These are 9 families that found themselves in the area of the City of Banja Luka, and they were provided with support in food and medicine, material resources and psychosocial support.

One of the activities that started immediately after the flood, and lasted for the next 18 months, is active participation in the project of rehabilitation of housing units that suffered as a result of the flood, which was carried out by UNDP. The task of the professionals from CSW Banja Luka was to review the overall social situation and make an assessment, on which basis persons that applied were awarded a donation in the form of rehabilitation of a housing unit. This assessment was preceded, among other elements, by a field visit to the household. More than 300 households applied for the programme announced by the UNDP, which means that the CSW conducted over 300 home visits and many more interviews with the household members.

\section{Organizing and providing psychosocial assistance and support after the flood}

Disasters affect large numbers of people whose lives, health or safety are endangered, leading to the destruction of property and the disruption of normal activities in the community. Floods, as a form of natural disaster, are not part of everyday, ordinary human experience, are unpredictable, and as sudden, unpleasant traumatic events cause fear, helplessness and horror, and lead to suffering for most people, regardless of their psychophysical condition and coping. . Reactions to traumatic events are inevitable and universal, very similar in most people, and specific symptoms depend on age, the nature of the traumatic experience and the significance they have for the individual (Čaldarević, 1995). There is a difference in the type and intensity of reactions to trauma, as well as the time it takes for people to recover.

People are generally unprepared for floods. They represent rare traumatic events that can be triggers for crises. It is important to note that, although at the root of every crisis is event that are highly stressful or traumatic, yet stress and trauma do not necessarily lead to a crisis. In order for a crisis to develop a feeling of helplessness, loss of control and internal balance, and disorganization of behaviour must be present. Both victims and helpers may experience reactions that are a sign of the development of a psychological crisis, and which often do not receive the necessary attention. A large-scale crisis event requires the engagement of a larger number of experts and services, their fast, precise and coordinated action. According to Dejan Ajduković, when a crisis occurs, the primary goal is to mitigate its impact (saving lives, safety and health care, saving property), then to eliminate the consequences as soon 
as possible and establish a normal level of functioning of individuals, groups and communities. The same author further points out that "immediately after people are rescued, injured are taken care of, and property is insured, it becomes obvious that in terms of feelings, opinions, bodily signs and overall functioning, the situation is not stabilized. People's reactions can be a sign of the development of a psychological crisis. They are recognized both by the immediate victims and by the helpers/professionas that participated in providing assistance or witnessed the events (Ajduković, D., 2000: 94). In accordance with the above, once they are placed in a safe place, it is necessary to provide psychosocial help and support to both victims and professionals. Also, Pregrad (1996) believes that it is necessary to first provide material and somewhat social care to people in order to successfully provide them with psychological assistance, and states that "Maslow's following model of personality development is clear that there is not much benefit from working on respect, acceptance, self-esteem and self-actualization if the basic biological, existential needs and the needs for security and predictability are not met "(Pregrad, 1996: 88).

It is indisputable that it is necessary to provide material, as well as social and psychological assistance during and immediately after the crisis events. Pregrad (1996: 87) proposes the division of the total area of psychosocial assistance into three sub-areas: crisis psychosocial intervention (shorter crisis intervention), psychosocial support and psychotherapy.

Crisis psychosocial intervention is applied immediately after crisis events that occur suddenly and abruptly and goes beyond the ordinary human experience, and to which individuals and groups cannot readily, effectively and psychologically respond sufficiently defensively (Pregrad, 1996: 87). These crisis events include, but are not limited to, natural disasters such as floods. Psychological crisis interventions are not psychotherapy, but are in fact preventive procedures aimed at alleviating traumatic stress, helping people to more easily endure traumatic events and to integrate them into their daily experience, which is necessary for their further normal functioning. Eranen and Liebkind (1993, according to Arambašić, 2000) define psychological crisis interventions as a set of procedures that are used to help people overcome what they have experienced after crisis events. Psychosocial crisis interventions provide support and assistance to people to regain a sense of autonomy and control over life. Vlajković (2009), as the most frequently used models of crisis interventions, states: concise psychological integration of trauma, relief and demobilization.

The goal of psychosocial support is to provide support to people, take on some of their tasks until they cope with the new situation and strengthen their own capacity to cope with stress. It is important to accept themselves as they are at the time, to accept part of their responsibility, but at the same time it is necessary to strengthen their coping capacity with stress and the new situation, and support them to take responsibility 
for meeting their own needs. This is a role of helper/professional. According to Pregrad (1996: 89), when providing psychosocial support, professionals must not insist too early on taking responsibility and to leave people enough space to process personal painful experiences, as this can create a sense of misunderstanding, rejection or injustice.

Psychotherapy is carried out with people who have symptoms of post-traumatic stress disorder, as well as with people whose psychopathology has been present for a long time and makes it difficult to adapt to the new situation.

Although reactions to traumatic events are universal, the way individuals react reacts to a person's level of sensitivity to stress, the dimensions of the traumatic event (natural or man-made, duration, complexity, number of people affected, the possibility of recurrence), but also from the level of support they receive from other people and the way they experience the support they receive. Given that traumatic events bring people into a state of complete helplessness and create a sense of insecurity for life, it is especially important that the traumatized feel safe when providing support and assistance after traumatic events. It should be noted that an event that causes a crisis in one person will not necessarily cause a crisis in another person and that, regardless of the fact that crises lead to mental confusion, disorganized behaviour and overwhelmed with feelings, people in crisis are open to psychological interventions (Arambašić, 2000 ).

In the CSW Banja Luka during and immediately after the flood, all human resources and potentials were used to provide psychosocial assistance and support to victims of natural disasters. These interventions mainly had the characteristics of short-term crisis interventions and the characteristics of psychosocial support that were realized in the field and immediately after the first intervention with persons who were endangered. Immediately after the floods in June 2014, the Ministry of Health and Social Welfare of Republic of Srpska, in cooperation with the Association of Psychologists of Republic of Srpska, activated the "Psychological Counselling Phone", which aimed to improve the provision of psychosocial support and assistance to the overall population.

\section{Psychosocial help and support for professionals}

Although social workers and other professionals in CSW in providing help and support to people in need are often exposed to events that disturb them, which can be threatening for them and can even cause post-traumatic stress reactions, crisis events can still be say they are not part of their daily professional experience. The fact is that the professionals in the CSW are not adequately prepared to act in emergency situations, in which the lives and health of a large number of people are endangered, but also their lives and health. They are not trained as police officers, firefighters and ambulance workers, so they can be confused or inappropriate at this kind of environment. For these reasons they are more likely to suffer from professional 
burnout and psychological crises. Indirect trauma also may occur in helpers/professionals due to exposure to other people's traumatic experiences, which have a traumatic effect on helpers. Hotkinson and Stewart (Hodkinson and Stewart, 1991, according to: Arambašić, 2000) talk about the superman reaction, about the behaviour of professionals who function well while at work, and the symptoms of indirect trauma appear when they come home. Because of this, it is necessary for professionals to understand the crisis as a mental state, to know the basic principles of crisis interventions, to be able to recognize crisis situations in their work, their own crises and their impact on their way of work.

Arambašić (2000: 34-35), emphasise that good preparation for supportive work implies "mastering theoretical knowledge about crisis, crisis interventions, acquiring skills of crisis interventions, developing understanding of crisis through expanding personal knowledge about its impact on personal and professional life". Crisis intervention models are specific procedures that are primarily intended for helpers, whose goal is to prevent the deterioration of their mental state, to mitigate and reduce long-term psychological, social and physical consequences, and to speed up the recovery process. Psychological crisis interventions can successfully alleviate or prevent psychological difficulties due to exposure to a crisis event.

Certain number of the professionals from CSW Banja Luka, who were involved in the protection and rescue of the people in the areas affected by flood during the emergency situation in the City of Banja Luka, were included in the psychosocial support and assistance program. This program was designed, coordinated and implemented by the Association of Psychologists of the Republic of Srpska, with the help of the Ministry of Health and Social Welfare, and donors who supported its implementation.

\section{Conclusions and recommendations}

The participation of the CSW Banja Luka is an unavoidable element in the analysis of system institutional activities in rescuing and caring for the people that found themselves in a state of social need caused by the catastrophic floods during 2014. The manner of organization, implementation of activities, and coordination of actions with the crisis headquarters, communication and direct provision of services to beneficiaries are the key elements that determine the participation of CSW Banja Luka in the rescue process. CSW Banja Luka had activities that they were implemented and placed CSW Banja Luka as a significant subject in defining an adequate response to the people needs during natural disasters. In the preparatory phase, the CSW Banja Luka adopted the Plan for protection and rescue from natural disasters and other accidents, which created the preconditions for adequate action in case of an emergency situation. After the declaration of the state of emergency, CSW Banja Luka went through three phases of action during the emergency situation:, phase of activation, phase of urgent action and the phase of stabilization. CSW Banja Luka had 
rehabilitation phase that in some segments lasted much longer than the phase of material rehabilitation conducted by the local government.

It should be noted that the management of the CSW Banja Luka tried to take all measures of protection and support of the population that were provided by the Law on Protection and Rescue in Emergency Situations of the Republic of Srpska, as well as the Law on Social Protection. In this regard, the CSW Banja Luka carried out the following activities:

detection and direct monitoring on the field with a special focus on the state of social needs of victims of natural disasters,

assessment of the living condition and needs of people affected by the natural disaster,

measures implementation monitoring during the action phase, preparation of reports, analyses and other information for local government bodies, proposing measures for situation improvement, encouraging, organizing and coordinating professional and voluntary work with affected,

developing local projects to solve specific social problems, cooperation with donors, organizing and providing psychosocial assistance and support to beneficiaries and providing psychosocial assistance and support to the employees of the CSW Banja Luka.

It is especially important to note that the CSW Banja Luka successfully responded to the organizational and professional challenges. Specifically, at the end of 2014, the CSW Banja Luka had approximately 800 more beneficiaries in the total number of beneficiaries of social protection, who were recruited from flood-affected areas in the City of Banja Luka, They came to a state of social need as consequences of the flood, and thus fulfilled the conditions for exercising certain rights from the Law on Social Protection.

The experience of the CSW Banja Luka and the direct engagement of professionals in the field indicate that it is necessary to expand the scope of activities that improve the direct practice of social work and social protection in situations of natural disasters. The following activities and tasks are necessary as desirable in the future operation of all CSW at the territory of the Republic: 
Improvement of Plan for protection and rescue from natural disasters and other accidents in the CSW in the Republic of Srpska, which would include monitoring and evaluation,

Education of professionals in social protection for dealing with and implementing activities in emergency situations,

Development of a general plan of crisis interventions in the CSW, as well as special plans for different types of crisis events,

Psychosocial assistance and support procedures for victims, as regular activities in post-crisis action plans,

Provision of adequate support and assistance to the professionals who are facing crisis events or are in a state of crisis, as a part of an Action plan,

Support plans should involve all organizations and institutions in the local community in whose competence is the organization and provision of assistance,

The plan should contain all specific tasks that the CSW faces immediately after crisis event, tasks that must be completed a few days after the event (psychological assistance), as well as tasks that must be completed in a few months after the crisis (systemic provision of assistance and support to persons identified as particularly vulnerable),

Make a plan for assessing the success of the implemented crisis interventions,

Mobilization of all experts who are trained to provide psychosocial support and assistance at the local community level and coordinate their work, when drafting a Crisis intervention plan,

Plan to implement continuous psychological support and assistance to victims and professionals,

Training of CSW in professional and material sense to act in crisis situations,

Representatives of CSW need to be part of in crisis headquarters municipal

Integrate the activities of the CSW into the Law on Protection and Rescue of the Republic of Srpska.

The analysis of the activities of the CSW Banja Luka indicated the limited possibilities of the social protection system during the emergency situation caused by natural disasters. However, insufficient recognition of the importance and role of CSW by other subjects continues to be an obstacle to achieving the full acting capacity of CSW during emergencies. Therefore, in the coming period, it is necessary to intensify cooperation with all those involved in the rescue process at the local community level. 


\section{Literature}

[1] Ajduković, D. (2000). Psychological crisis interventions in the community in: Arambašić, L. (ed.), Psychological Crisis Interventions (pp. 93 - 120). Zagreb: Društvo za psihološku pomoć.

[2] Ajduković, M (2000). Crisis events and crisis as a mental state in: Arambašić, L. (ed.), Psychological Crisis Interventions (pp. 33 - 56). Zagreb: Društvo za psihološku pomoć.

[3] Arambasic, L. (2000).Psychological crisis interventions. Zagreb: Društvo za psihološku pomoć.

[4] Buljubasic, S., at all. (2015). Manual for the operation of the Centers for Social Work in emergencies caused by natural disasters. UNICEF Sarajevo: RS Ministry of Health and Social Protection of Republic of Srpska Government and the Federal Ministry of Labor and Social Policy

[5] Čaldarević, O. (1995). Social theory and gambling. Zagreb: Croatian Sociological Society.

[6] Annual work report of the PI Center for Social Work Banja Luka (2014).

[7] Plan for protection and rescue from natural disasters and other accidents (2013). PI Center for Social Work Banja Luka.

[8] Pregrad, J. (1996). Stress, trauma, recovery. Zagreb: Društvo za psihološku pomoć.

[9] Decree on the content and manner of drafting a plan for protection against natural and other disasters ("Official Gazette of the Republic of Srpska" No. $68 / 13)$

[10] Vizek - Vidović, V. and Arambašić, L. (2000). Psychological crisis interventions in: Arambašić, L. (ed.), Psychological Crisis Interventions (pp. 57 - 92). Zagreb: Društvo za psihološku pomoć

[11] Vlajkovic, J. (2005). Life crises. Prevention and overcoming. Belgrade: IP "Zarko Albulj.

[12] Vlajkovic, J. (2009). From victim to survivor. Belgrade: IP "Zarko Albulj.

[13] Law on Social Protection of the Republic of Srpska ("Official Gazette of the Republic of Srpska" No. 32/12 and 90/16).

[14] Law on Protection and Rescue in Emergency Situations of the Republic of Srpska ("Official Gazette of the Republic of Srpska" No. 46/17). 